\title{
"GET-UP" study rationale and protocol: a cluster randomised controlled trial to evaluate the effects of reduced sitting on toddlers' cognitive development
}

\author{
Rute Santos ${ }^{1,2^{*}}$ D, Dylan P. Cliff ${ }^{1}$, Steven J. Howard ${ }^{1}$, Sanne L. Veldman ${ }^{1}$, Ian M. Wright ${ }^{1,3}$, Eduarda Sousa-Sá1,
} João R. Pereira ${ }^{1}$ and Anthony D. Okely ${ }^{1}$

\begin{abstract}
Background: The educational and cognitive differences associated with low socioeconomic status begin early in life and tend to persist throughout life. Coupled with the finding that levels of sedentary time are negatively associated with cognitive development, and time spent active tends to be lower in disadvantaged circumstances, this highlights the need for interventions that reduce the amount of time children spend sitting and sedentary during childcare. The proposed study aims to assess the effects of reducing sitting time during Early Childhood Education and Care (ECEC) services on cognitive development in toddlers from low socio-economic families.

Methods/Design: We will implement a 12-months 2-arm parallel group cluster randomised controlled trial (RCT) with Australian toddlers, aged 12 to 26 months at baseline. Educators from the ECEC services allocated to the intervention group will receive professional development on how to reduce sitting time while children attend ECEC. Participants' cognitive development will be assessed as a primary outcome, at baseline and post-intervention, using the cognitive sub-test from the Bayley Scales of Infant and Toddler Development.
\end{abstract}

Discussion: This trial has the potential to inform programs and policies designed to optimize developmental and health outcomes in toddlers, specifically in those from disadvantaged backgrounds.

Trial registration: Australian New Zealand Clinical Trials Registry: ACTRN12616000471482, 11/04/2016, retrospectively registered.

Keywords: Sedentary behaviour, Physical activity, Childcare, Executive function

\section{Background}

The early years are critical in setting the trajectory of an individual's life. Healthy child development up to the age of 5 years provides the basis for a prosperous and sustainable society [1]. The material and psychosocial context of poverty adversely affects multiple aspects of development in children $[2,3]$ and developmental deficits associated with poverty start before birth and can be detected as early

\footnotetext{
* Correspondence: rutes@uow.edu.au

${ }^{1}$ Early Start Research Institute, School of Education, Faculty of Social Sciences, University of Wollongong, Northfields Avenue, Wollongong, NSW 2522, Australia

${ }^{2}$ Research Centre in Physical Activity, Health and Leisure, Faculty of Sport, University of Porto, Porto, Portugal

Full list of author information is available at the end of the article
}

as infancy $[4,5]$. The best available knowledge on the basic principles of neuroscience indicate that providing supportive conditions for early childhood development is more effective and less costly than attempting to address the consequences of early adversity later [3]. Indeed, early life experiences from birth to school entry are essential to build strong neurodevelopmental trajectories crucial for long-term social and occupational functioning [6].

Specifically, the first 5 years of life are important for the development of executive functions (EFs). EFs are often conceived as higher-order cognitive control processes, which consist of three inter-related functions. 
The first, working memory, is involved in "holding information in mind and working with it" [7], which is important for everything from understanding language to mental mathematics and reasoning. Central to working memory is the activation of information via attention. Inhibition, by contrast, involves "inhibiting (or suppressing) attention [or action] to other things in the environment (distracters) so you can stay focused on what you want" [7]. Lastly, cognitive flexibility involves an ability "to shift mental sets or see something from different perspectives" [7]. Together, these cognitive control processes enable us to perform the full range of everyday and extra-ordinary tasks that are essential for adaptive human function.

The cognitive control provided by EFs is essential for the behavioural, emotional and social controls that contribute to positive life trajectories. That is, ample research has indicated a link between EFs and school readiness, academic success, social and emotional development, criminality and employment success [7]. Moreover, in the largest prospective study of self-regulation conducted thus far conducted so far (1000 children who were followed from birth to age 32), it was reported that childhood self-control (at ages 3 to 11) predicted better physical health, less substance dependence, higher personal finances and less criminal offending outcomes in adulthood, following a gradient of self-regulation, even after adjusting the analysis for IQ, sex, and social class while growing up [8]. More than fixed trajectories of self-regulatory development, this study also demonstrated the malleability of self-regulation over time, as well as improved trajectories when this occurred.

Early EFs are also considered the "biological foundation for school readiness" [7, 9] and a better predictor of academic achievement than IQ [10, 11]. It has been shown that EF skills at the age of 4 years provided children with an immediate advantage in the school learning environment and a head start in maths and reading that was maintained through to the age of 7 years [12]. Fitzpatrick et al. [13] reported that early working memory (at the age of 29 and 41 months) predicted later (at 74 months of age) classroom engagement, number knowledge and receptive vocabulary, independent of sex, non-verbal intellectual skills and socio-economic status.

Cognitive development is affected by several socioeconomic and environmental factors. Disadvantaged children usually experience less cognitive stimulation and enrichment, watch more television, attend lower quality childcare, and have poorer diets [14]. These children may also be exposed to stressful environments and receive less warmth, stability and support from their families [14]. The cumulative effect of these risk factors during a sensitive period of brain expansion and growth can compromise neurocognitive development [5, 15]. Indeed, the educational and cognitive differences associated with low socioeconomic status begin early in life and tend to persist throughout life $[11,16]$. For example, Lipina et al. [4] reported that infants (aged 6 to 14 months) from disadvantaged families had, on average, less developed working memory and inhibitory control abilities compared to those from non-disadvantaged families. Evans and Schamberg [17] also reported a prospective association between the duration of childhood poverty and adult working memory, an association that appeared to be explained in part by elevated chronic stress during childhood. Therefore, targeting EF, in early childhood in order to improve school readiness and later academic success seems crucial [18] and may constitute an important tool to reduce the academic achievement gap between more and less-advantaged children.

In a 2011 review, Diamond and Lee [18] identified six types of interventions that successfully improve EFs in children aged 4 to 12 years: computerised training; a hybrid of computer and noncomputer games; classroom curricula; adds-ons to classroom curricula; aerobic exercise and martial arts and mindfulness practices. These interventions have revealed that: (i) children with lower EF (including those from socially disadvantaged backgrounds) benefit the most from any EF intervention; (ii) EF training in one area seems to transfer to other EFs, but this transfer is limited; and (iii) executive demands need to be repeated and continually incremented $[7,18]$. All of these interventions have two important features in common: first, "the programs tend to reduce stress in the classroom, cultivate pride, joy and self-confidence, and foster social bonding"; and second, "they do not expect children to sit still for long-such expectations are not developmentally appropriate, increase teacher-student tensions, and lead some children to dread school and/or to be wrongly labels as having Attention Deficit and Hyperactivity Disorder (ADHD)" [18].

Although these types of interventions have been successful from 4 years of age, recent evidence recommends that they should start even earlier than the pre-school period-i.e. between 1 and 2 years of age-to attenuate the impact of disadvantage on the children's cognitive development $[19,20]$. New ideas and new approaches are therefore necessary [21].

It has been long recognised that PA is positively associated with cognitive performance in school-aged children (aged 4 to 18 years) [22] and across the lifespan [23]. In infants, passive cycling for 2 months during the first year of life resulted in positive motor (body control balance, grasping), adaptive (hand-eye coordination) and language gains (communication by facial expression, sounds, vocalizations, and babble) compared to controls [24]. 
Early childhood is also a critical period to establish long-term sedentary and physical activity (PA) behaviours [25]. Sedentary behaviour (SB) refers to waking activities that do not increase energy expenditure substantially above the resting level, while in a sitting or lying position [26]. It has been suggested that SB should be explicitly measured either for surveillance purposes or research studies instead of being defined as lack of PA [27] as sedentariness and PA are two independent and not mutually exclusive behaviours with potentially different effects on development and health outcomes [28-31].

Studies assessing PA and SB levels in infants and toddlers are scarce [32], particularly using objective measures of PA and SB. Recently, Cardon et al. [32] summarised the literature and reported that PA rates are low, infants and toddlers spend a large proportion of their time being sedentary. Television viewing is already common at these ages. For example, in the US it is estimated that $17 \%$ of $0-11$ month old and $48 \%$ of $12-23$ months old children exceed the American Academy of Pediatrics guidelines ( $<2 \mathrm{~h} /$ day) [33] and that $40 \%$ of 3 months old babies and $90 \%$ of 2 years old toddlers watch TV regularly [34]. Some studies have shown that PA levels of children aged 0 to 5 years are typically low and SB high [35-37]. In a meta-analysis of objectively measured PA, Bornesteins et al [38] reported that preschoolers spend on average only $5.5 \%$ of their waking time in moderate-to vigorous-intensity PA. Australian pre-school children also are characterized as highly inactive, with only $5 \%$ meeting the current national recommendations of $3 \mathrm{~h}$ /day of PA [39]. ECEC settings may be extremely inactive and sedentary environments [40] with children spending only $15 \%$ of their childcare day engaged in PA [41] and up to $80 \%$ of their day in sedentary activities [42]. This suggests that young children may not be provided with the opportunity to move in ways that are natural and developmentally appropriate even at ECEC centres. This is particularly concerning, given that several studies have reported beneficial associations between PA and several health indicators and developmental aspects in early childhood $[43,44]$ and also the deleterious health effects of excessive SB [44].

High levels of SB (particularly screen time) during early childhood have shown to be associated with higher adiposity [44, 45], higher blood pressure [46], less bone accrual [47], attention problems [48] language development [49], psychosocial health $[44,50]$ and cognitive development $[44,51]$. However, a recent systematic review showed that different types of SB may have different associations with cognitive development during early childhood: reading/being read to was positively associated with cognitive development in contrast to screenbased activities [51]. Moreover, a longitudinal study has documented that the time spent watching television under the age of five was negatively related to cognitive development, short-term memory and academic achievement 1 to 3 years later [52].

Evidence suggests that there are several neurological pathways that may explain the adverse links between sitting and cognitive development [30]. These include pathways involving the birth of new neurons (neurogenesis) that occurs mainly in the hippocampus, a critical area in the brain for learning and memory processes. Prolonged sitting may promote increased activation of stress systems through its rapid effect on metabolic and inflammatory pathways, and chronic stress activation may slow the rate of neurogenesis. Sitting may also negatively affect synaptic plasticity (creation of new or strengthening of existing synaptic connections during learning) through pathways involving insulin and adipose-driven leptin. Additionally, Growth Factors (BDNF, VEGF, IGF-1) play multiple roles in the survival and maturation of new neurons, which are critical for neurogenesis, synaptic plasticity and angiogenesis (growth of new blood vessels); over-abundance of insulin caused by prolonged sitting may suppress systemic IGF-1 signaling that promotes neuronal growth and repair. Since insulin-sensitivity is disrupted shortly after breaking up prolonged sitting, IGF-1 signaling may also be affected. It is known that PA improves cerebral blood flow due to increases in artery diameter, the sprouting of new capillaries from existing vessels, and the bioavailability of endogenous nitric oxide. It has been hypothesized that prolonged sitting decreases nitric oxide and may promote endothelium dysfunction [30]. Despite this evidence, the influence of PA and $\mathrm{SB}$ on cognitive development in toddlers remains poorly understood [44].

In this context, and in an attempt to respond to recent calls on innovative approaches and fresh thinking on how to improve cognitive development in disadvantaged children [21], the primary aim of this study is to assess the effects of reducing sitting time during ECEC on cognitive development, in a cluster randomised controlled trial with toddlers from low socio-economic families. It is hypothesized that at 12-month follow-up, toddlers in centres allocated to the intervention group will have improved their cognitive development by $0.5 \mathrm{SD}$ more than toddlers in ECEC centres randomly allocated to the control group. The secondary aims are to examine the effects of reducing sitting time on toddler's cardiovascular health and bone density.

\section{Methods}

\section{Study design}

We will implement a 12-months 2-arm parallel group cluster randomised controlled trial. Cluster randomization was chosen for practical reasons and to prevent contamination. The selection of the ECEC services (clusters) will be based on the ECEC' postcode using the Australian 
Socio-economic Indexes for Areas 2011 (SEIFA-Index of Relative Socio-Economic Disadvantage) [53]. We will consider the centres belonging in the first and second quartile of this Index (extreme-low and moderate-low socio-economic status) in the Illawarra Region, NSW, Australia. Eight services will be randomly allocated to the intervention group and eight to the control group.

\section{Study context}

Early childhood education and care for toddlers is not compulsory in Australia. Australian children in their toddler years are enrolled in Child Care by their families' choice. In Australia, $22.2 \%$ of children aged $0-1$ year and $54.1 \%$ of children aged 2-3 years attend formal care at least once a week (http://www.abs.gov.au).

There are four types of formal care in Australia being Long Day Care, Occasional Care, Family Day Care and In Home Care; these services must be registered and approved by the Department of Education and Communities to operate. The Government in each state regulates Child Care Services. The following standards of practice in Child Care are adhered to: The National Childcare Accreditation Council Standards; Education and Care Services National Regulations; Children Education and Services National Law Act 2010; the Early Years Learning Framework; the United Nations Conventions on the Rights of the Child and the Australian Early Childhood Code of Ethics. In Australia the ratio educators/childcare workers per child is $1: 4$ for 0 to 1 year-olds and 1:8 for 2 to 3 year-olds (www.acecqa.gov.au).

ECEC services in Australia are income tested. Families earning under \$152,147/annum with one child are able to apply for Child Care Benefit and Child Care Rebate from the Government. The income threshold goes up with each additional child in the family. However, the eligibility for this benefit is also dependant on the child's immunisation status. The average fee for a Long Day Care service is $\$ 102 /$ day (www.abs.com.au).

Some Long Day Care Services provide all the necessary meals of (breakfast, morning and afternoon tea and lunch) whilst others may provide only a snack and parents are required to bring lunch and other snacks. In the option of the latter, these services charge a lower fee than those whom provide meals.

For the purpose of this study data will be collected only in Long Day Care Services in NSW.

\section{Ethics statement}

The University of Wollongong's Human Research Ethics Committee approved the study (HE15/236) and this RCT was registered in the Australian and New Zealand Clinical Trials Registry (ACTRN12616000471482, 11/04/ 2016, retrospectively registered) (see Additional file 1: Table S1 for trial registration data details). Informed written consents will be obtained from the Educators and children's parents or guardians. The study will be conducted according to the Helsinki Declaration for Human Studies [54].

\section{Participants and protocol Inclusion criteria}

This RCT will comprise 16 ECEC services from Illawarra region in NSW, each of which must have at least one class of at least 20 toddlers, from a low- to mediumsocioeconomic background [53]. All apparently-healthy toddlers aged 12- to 26-months at baseline will be eligible to participate if they attend the ECEC service at least twice per week. We expect to recruit 18 participants per childcare services. Children will be considered ineligible if they have a learning or physical disability, born very preterm $(<29$ weeks of gestation) or have a diagnosed medical or psychological condition that would affect the results of this study.

\section{Recruitment}

After determining the eligible ECEC services, we will perform a simple randomisation using a computerised sequence generation to determine the order in which eligible ECEC services will be invited to participate in this study. Invitations will be performed by email and by phone, requesting a face-to-face meeting with service Director to outline the aims and procedures required for this RCT.

If a selected ECEC service declines participating in the study, an additional phone call and face-to-face meeting will be made to the next eligible service on the list until 16 childcare services agree to participate in this RCT.

All toddlers enrolled in each class/ECEC centre will be invited to participate in the study. We will send an invitation letter and an information sheet outlining the aims and procedures of the study to the toddler's parents or guardians. While no exclusion criteria will be applied for participation in the study, to prevent any discrimination, for analysis and reporting only toddlers eligible according to the aforementioned inclusion criteria will participate in the study.

\section{Intervention}

The intervention is based on Bandura's Social Cognitive Theory [55], which has been used extensively in behaviour change interventions. Social Cognitive Theory posits that behaviour is learned, modified and sustained through the interplay of personal, behavioural and environmental factors. The intervention will focus on these factors and how they influence sitting behaviours. All components of the intervention have been designed to address the four key learning processes suggested by Bandura [56] to enhance behaviour change (attention, retention, 
production, motivation). The intervention has also been designed to target Social Cognitive Theory mediators, such as educator self-efficacy [57].

The intervention has been designed in response to formative research conducted by the authors within similar ECEC services in disadvantaged locations. In 2013, 12 focus groups were held with educators from 11 services. Educators were provided with data on how much time children in their service spent sitting and asked to identify by how much they would like to reduce this proportion of time. The most common reduction was $50 \%$ of the time currently spent sitting. Based on the proportions presented above, this would result in reducing a "typical" day (50\% of the time in childcare spent sitting) to $25 \%$ of the time spent sitting. Educators were then asked to complete a daily routine log for their service, which described the modifications that would take place to allow the halving of time spent sitting. Researchers then provided further ideas. The ideas provided by educators largely focused on changes to practices and modifications to the physical environment. Included in these ideas were ways to ensure no bouts of sitting exceeded $15 \mathrm{~min}$. These example schedules will be used by each of the intervention ECEC services to design their own daily schedule to reduce total sitting time by $50 \%$ and to reduce bouts of sitting to $<15 \mathrm{~min}$.

We mapped the intervention step-by step as proposed by Robinson and colleagues [58]. We began by identifying the target behaviours and then worked backwards to define activities and strategies and potential mediators. (see Figs. 1 and 2). To attain our goal of improving toddler's executive functions we will implement four main strategies, which are based on the principles of the Bandura's Social Cognitive Theory: (i) Professional Development for Educators, (ii) Provision of Resources and Instrumental Materials (ii) Follow-up Support and (iv) Performance Monitoring and Feedback (as described in detail in Table 1), to reduce toddler's total sitting time by $50 \%$ and to reduce bouts of sitting to less than 15 min, while toddlers are in the ECEC centre.

Table 2 describes in detail the main activities to be proposed to the educators attending the professional development workshop. As explained in Table 1, after the professional development workshop further activities on how to reduce total sitting time and sitting bouts can be added to this list. The initial list of activities presented in Table 2 includes changes in routine activities, changes in the indoor environment and changes in the outdoor environment.

\section{Control Group}

The Control Group will continue with their usual program and will receive the intervention training and materials at the end of follow-up assessments.

\section{Assessment of the Outcomes}

Data collection will occur at baseline (before randomization) and at the end of the intervention (Fig. 3 Participants Timeline). For those children who have turned 3 at follow-up, an additional four executive function tasks will

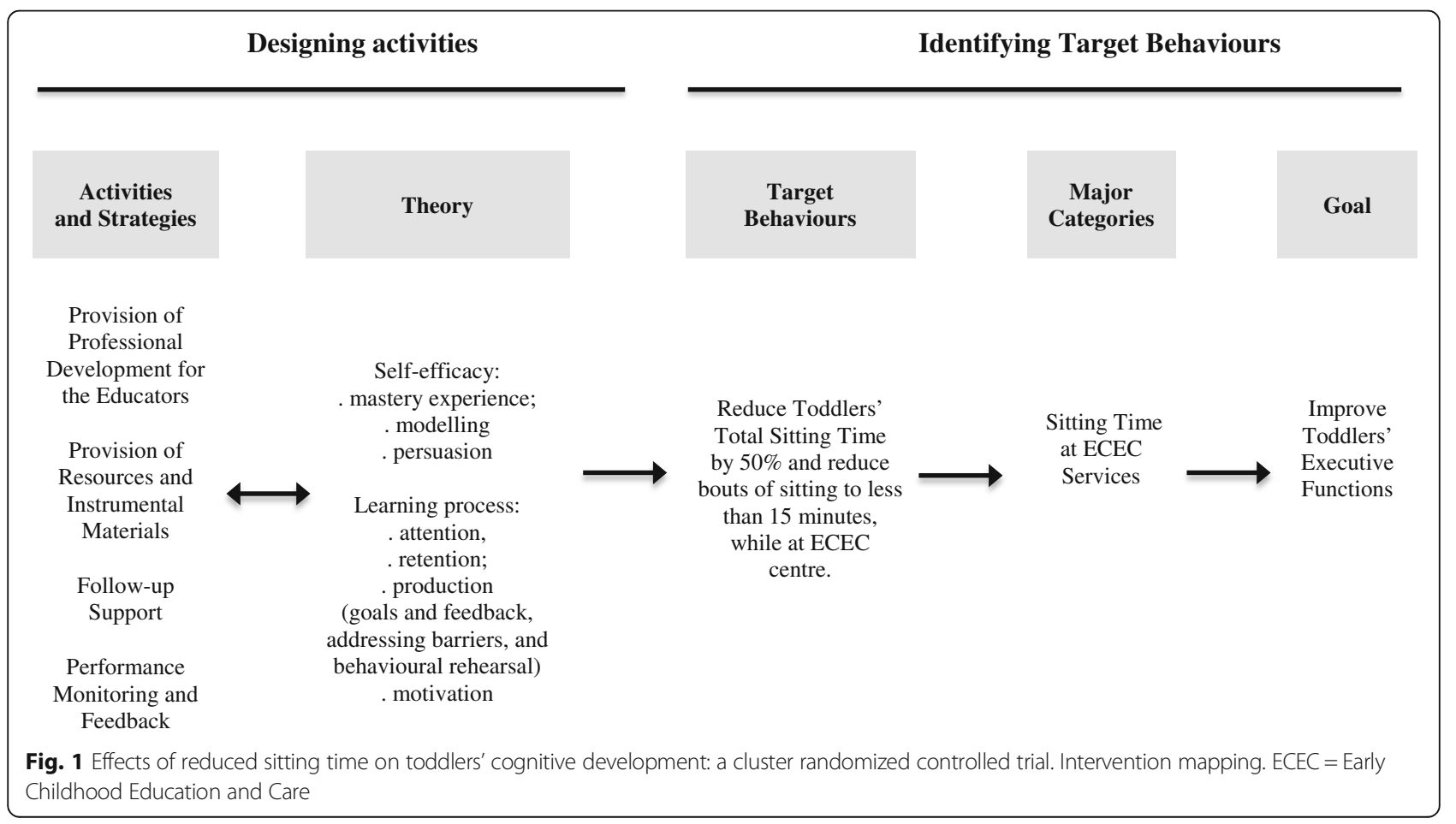




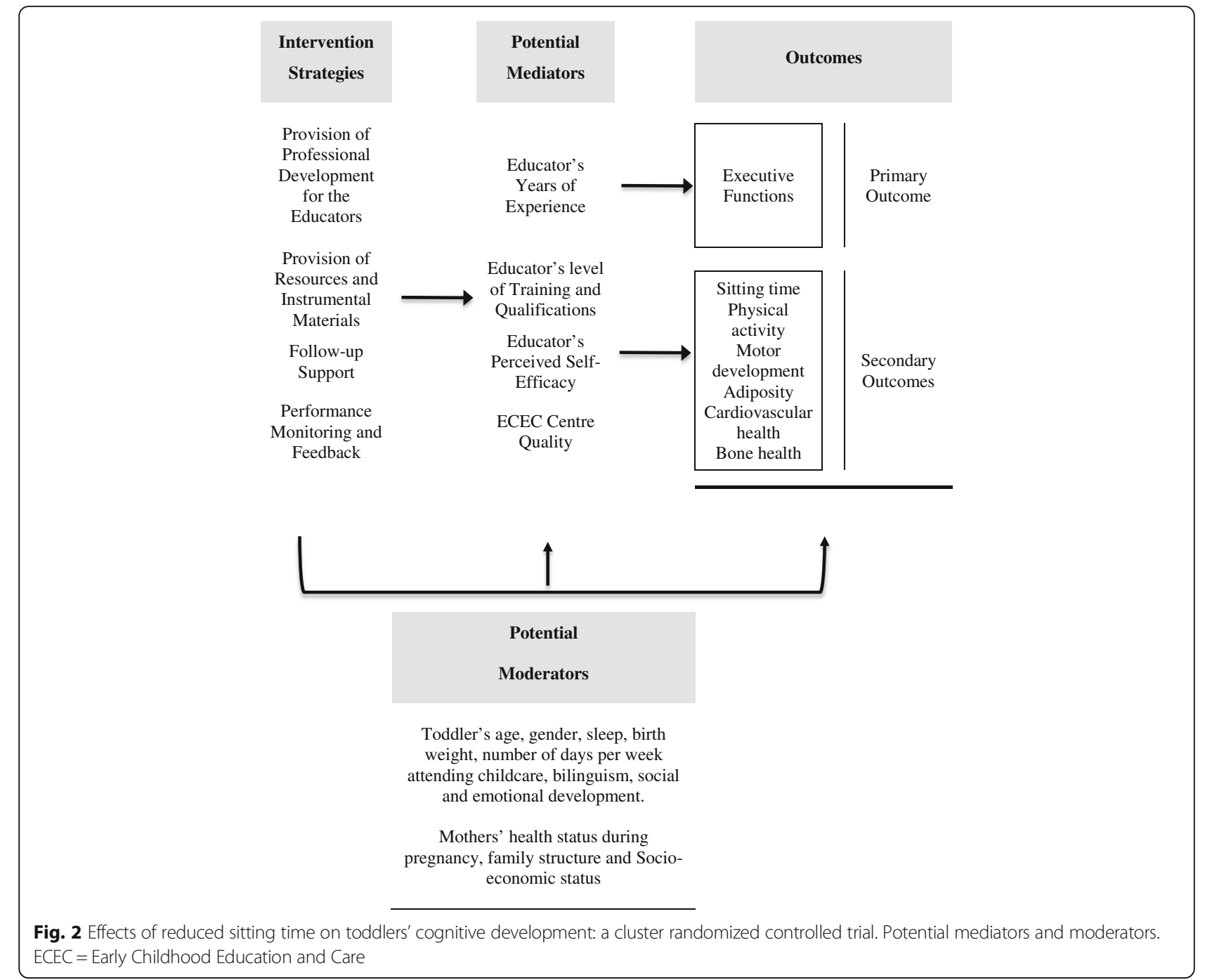

be collected as described below. Trained research assistants blinded to group allocation will collect all data.

\section{Primary Outcome}

Cognitive development Cognitive development and executive functions will be assessed using the cognitive sub-test from the Bayley Scales of Infant and Toddler Development-Third edition (Bayley-III) [59]. This subtest assesses sensorimotor development, exploration and manipulation, object relatedness, concept formation, memory, and problem solving. The Cognitive subset of the Bayley scales will be applied and scored according to standard procedures described in the Bayley-III manual for the age of the child at the starting point. For those children who have turned 3 at follow-up, an additional four executive function from the Early Years Toolbox will be used to ensure assessments are comprehensive. These iPad-based tasks assess the three core aspects of
$\mathrm{EF}$, and have been developmental and psychometrically evaluated with large samples of preschool-aged children [60]. All iPad apps have built-in auditory instructions so the data collectors could ensure the participant understood the instructions, clarified where necessary and remained on task.

The Early Years Toolbox go/no-go task [61] evaluates the ability to inhibit a dominant behavioural response in response to a less frequently presented 'no-go' stimulus. In this game, a child is asked to 'catch the fish' by tapping on the screen when they appear ('go' response) and 'avoid the sharks' by not pressing anything when the less-frequent sharks appear ('no-go' response). The task is evenly split into three mixed blocks of 25 stimuli, each consisting of $80 \%$ 'go' trials, so as not to exceed $1 \mathrm{~min}$ for each block and to provide participants with a short break between each block. Animated stimuli (swimming from left to right across the screen) are presented in random order for $1500 \mathrm{~ms}$ each, followed by a $1000 \mathrm{~ms}$ 
Table 1 Effects of reduced sitting time on toddlers' cognitive development: a cluster randomized controlled trial. Intervention strategies and activities and corresponding principles of Social Cognitive Theory

\begin{tabular}{|c|c|c|}
\hline Activities and strategies & Description & Principle of Social Cognitive Theory \\
\hline \multirow[t]{4}{*}{$\begin{array}{l}\text { Provision of Professional Development } \\
\text { for the Educators }\end{array}$} & $\begin{array}{l}\text { Educators will attend a } 6 \mathrm{~h} \text { professional } \\
\text { development workshop. The workshop } \\
\text { will begin by introducing the rationale } \\
\text { and aims of the study }(1 \mathrm{~h}) \text {. }\end{array}$ & $\begin{array}{l}\text { Self-efficacy: } \\
\text { mastery experience; }\end{array}$ \\
\hline & $\begin{array}{l}\text { Educators will then be asked to think } \\
\text { about ways to (i) modify routine activities } \\
\text { to reduce the total amount of sitting time } \\
\text { and reduce bouts of sitting to less than } \\
15 \text { min and (ii) to change indoor and } \\
\text { outdoor environment to reduce the total } \\
\text { amount of sitting time and the length of } \\
\text { the sitting bouts. }(1 \mathrm{~h}) \text {. }\end{array}$ & $\begin{array}{l}\text { modelling } \\
\text { persuasion }\end{array}$ \\
\hline & $\begin{array}{l}\text { After this activity, the educators will be able } \\
\text { to rehearsal some of the proposed activities } \\
\text { in our laboratory ( } 2 \mathrm{~h} \text { and } 30 \mathrm{~min}) \text {. }\end{array}$ & Learning process: \\
\hline & $\begin{array}{l}\text { Finally, educators will be given further ideas } \\
\text { on how to reduce toddlers' total sitting time } \\
\text { and reduce bouts of sitting to less than } \\
15 \text { min. Perceived barriers for the } \\
\text { implementation of the program and possible }\end{array}$ & $\begin{array}{l}\text { attention, } \\
\text { retention; } \\
\text { production (goals and feedback, addressing } \\
\text { barriers, and behavioural rehearsal) }\end{array}$ \\
\hline
\end{tabular}

Provision of Resources and Instrumental Materials

Follow-up Support

Performance Monitoring and Feedback solutions to overcome these barriers will be discussed (1.5 h).

We will aim to train all educators from each centre on the same day to ensure standardization of content delivery.

After the professional development workshop we will provide educators with supporting written materials with the rationale, aims and strategies/activities to reduce toddler's sitting time. We will provide them with posters to be displayed in their classroom as a reminder of the need to reduce sitting time. A video demonstrating the proposed activities and desired routine changes will also be provided.

During the intervention period the educators will receive monthly on-site visits from the research team, to revise key activities and behavioural strategies to reduce toddlers' total sitting time and to follow up on the activities that are being undertaken.

Three months and six months after the start of the intervention educators will attend an interactive online webinar to follow-up on the intervention, to share ideas and perceived barriers of the intervention implementation and to address possible solutions to overcome those barriers.

During the intervention period educators will also receive regular emails and telephone calls.

During the monthly visits the research staff will collect objective information on the total sitting time and sitting bouts (by accelerometry) in a random small sample of toddlers (10 \%) to monitor the implementation of the intervention. This performance will be delivered to the educators, providing feedback on the intervention implementation.

Learning process:
retention;
motivation
Self-efficacy:
modelling
Self-efficacy:
mastery experience;
. persuasion
. production (goals and feedback,
addressing barriers)
. motivation
Learning process:
retention;
. production (goals and feedback,
addressing barriers)


Table 2 Effects of reduced sitting time on toddlers' cognitive development: a cluster randomized controlled trial. Activities to be proposed to educators

\begin{tabular}{|c|c|}
\hline Activities & Description of the activities for the educators \\
\hline \multicolumn{2}{|l|}{ Routine activities } \\
\hline Action time story & $\begin{array}{l}\text { Role-playing stories. For example, when telling a story about a horse, every } \\
\text { time the children hear the word horse (or the horse character's name) they } \\
\text { have to jump up and pretend to be a horse for } 5 \mathrm{~s} \text {. Repeat this throughout } \\
\text { the story. The group can be broken up into smaller groups of frogs, } \\
\text { crocodiles, horses etc. Where each group has to stand up at only their } \\
\text { prompt. This activity works for Executive Function abilities-working } \\
\text { memory-as children have to remember what animal they are and it } \\
\text { decreases sedentary behaviour. }\end{array}$ \\
\hline Stand on a dot or a hoop to gather children as a group. & $\begin{array}{l}\text { Asking children to stand on a dot or in a hoop would replace sitting on the } \\
\text { floor to gather them as a group. This activity would still give the control and } \\
\text { structure of gathering and focusing the children, but reducing sitting time. } \\
\text { The children can also be gathered and asked to hold hands while waiting for } \\
\text { the others to arrive. In doing this children are making their own barrier and } \\
\text { focusing their attention on the group. }\end{array}$ \\
\hline
\end{tabular}

Musical painting table

Apply sunscreen with the toddlers standing Indoor environment

Locating play/learning spaces/areas near the wall

Standing table

Move pencils/brushes away form the painting table

Move bins away from the tables during meal times

Outdoor environment

Remove chairs and tables from the outdoor space

Use a tree in the yard as an easel

Painting along the fence with an old sheet

Provide equipment that does not promote sitting (ex. balls)
When the children are painting at a standing table, put on some music, after 2 min stop the music and the children have to put down their paintbrushes/ pencils and change spots around the table. Then the music starts and they start painting again. The painting can be done on a big sheet of paper on the table, or a sheet on the table, or on individual pieces of paper.

Have all children standing while applying the sunscreen.

By locating play/learning spaces/areas near the wall and leaving the centre of the room with an open space, children have increased opportunities to move freely from one place to other.

Remove the chairs away from the table so that the children can be standing while painting, doing puzzles or other activities.

Place the pencils and brushes in a separate table so that children can move from one table to other to change pencils/brushes.

Place the bins away from the tables during meal times, so that children need to walk to bin after the meals.

Remove all equipment that promotes sitting (chairs and tables) from the outdoor space

Attach paper to the tree and do chalk rubbings of the bark from the tree. Paper would be at standing height.

In warmer days, paint along the fence with an old sheet with the children standing.

During outdoors free play provide toddlers with equipment that does not promote sitting (ex. balls). interval between stimuli. Scores represent the product of proportional go and no-go accuracy.

The Early Years Toolbox Mr. Ant task assesses visualspatial working memory, or the amount of visual information that concurrently can be activated in the mind. The child is presented with an image of a cartoon ant, which has coloured dots on different spatial locations on his body. Mr Ant, with his coloured dots, is presented for five seconds, followed by a blank screen for four seconds, and then an image of Mr. Ant without any coloured dot appears and the participant indicates the recalled locations by tapping on the recalled locations. In the first level, with a single dot, children must remember a single spatial location. The task proceeds until the earlier of failure on all three trials at a given level of difficulty or level eight (with the location of eight coloured dots to recall). Performance is indexed by a point score, such that each successive level with at least two trials correct receives 1 point, and all correct trials thereafter receive $1 / 3$ of a point.

The third Early Years Toolbox task, a card sorting task, is a measure of cognitive flexibility (the ability to disengage and re-direct attention) [61]. In this task, children are presented with stimuli, one at a time, which vary in shape and colour (red rabbit and a blue boat). Children are asked to sort the shapes into castles 


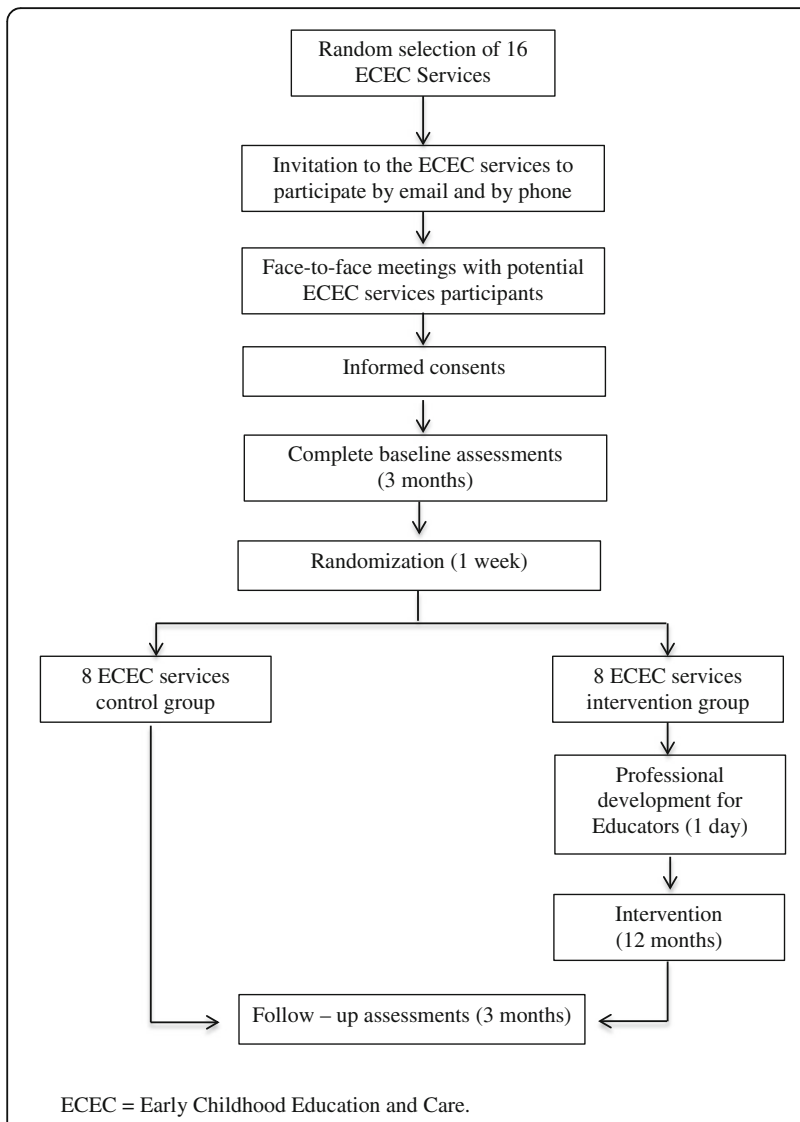

Fig. 3 Effects of reduced sitting time on toddlers' cognitive development: a cluster randomized controlled trial. Participants Timeline

(denoted by a blue rabbit and red boat) first by one dimension (colour) and then, after six trials, by another dimension (shape). Successful completion of at least five pre-switch and post-switch trials results in administration of a border version of the task, in which children must flexibly switch between these sorting rules depending on whether the stimulus does or does not have a border. Scores represent the number of correct trials once the initial switch has been made.

Cognitive assessments and EF tests will be conducted individually in a private area and will be scheduled on separate days, where possible, to minimise cognitive fatigue.

\section{Secondary Outcomes}

Sitting time Total time spent sitting and bouts of sitting during childcare hours will be assessed over a 1 week period using an activPAL accelerometer [62]. The activPAL (PAL technologies, Glasgow) is small (53 x $35 \times$ $7 \mathrm{~mm})$ and lightweight $(15 \mathrm{~g})$ and is placed on the front of the upper thigh (using a small hypo-allergenic adhesive gel patch, and covered with a transparent sticky film to secure it) allowing it to measure different postures (eg, sitting, standing). Concurrent and criterion validity of the activPAL for sitting time measures, as well as for interruptions (breaks-defined as the number of transitions recorded from "sit/lie" posture to "stand") in SB have been established for young children [62-64].

Physical activity and sedentary time Levels of physical activity and sedentary time over a usual week will be measured using Actigraph GT3X+ accelerometers. Actigraphs are small, light and unobtrusive devices worn on a belt around the waist. These accelerometers have established validity and utility in toddlers $[65,66]$. These devices can collect very high-frequency raw data $(30 \mathrm{~Hz})$, which will be reintegrated and analysed according to bestpractice methodologies at the time of analysis. Participants will be asked to wear the accelerometer for $24 \mathrm{~h}$ /day over 7 days (except for water activities), and parents will be asked to register in an activity monitor log the times that the accelerometers was removed from the child.

Demographics Demographic and family lifestyle variables will be assessed with a family survey. This survey will include the following variables: parents/caregiver' age, gender, marital status, Indigenous/Torres Strait Islander origin; child's gestational age at birth; family structure and family socio-economic status. Family socio-economic status will be assessed by the family postcode address using the Australian Socio-economic Indexes for Areas 2011 (SEIFA-Index of Relative Socio-Economic Disadvantage) [53] and also with a modified version of the Graffar index [67] which includes the highest level of schooling completed, income, main source of income and type of employment (job title). The family survey will also assess parental height and weight and smoking and alcohol habits $[68,69]$.

Sleep Sleeping patterns will be assessed with the Tayside Children's Sleep Questionnaire [70, 71]. This 10-item scale evaluates the child's ability to initiate and maintain sleep. The family survey also asks parents to report their child's total sleeping time per day. Sleep duration will also be objectively measured with the Actigraph GT3X+ accelerometers.

Psychological adjustment Educators will assess children's psychological adjustment with the extended version of the Strengths and Difficulties Questionnaire (SDQ). This questionnaire asks about the emotional symptoms, conduct problems, hyperactivity-inattention, peer problems and pro-social behaviour of the child $[72,73]$.

Anthropometrics We will measure weight, height and waist circumference according to standard procedures 
[74]. Body height will be measured to the nearest $0.1 \mathrm{~cm}$ in bare or stocking feet with the child standing upright against a portable stadiometer (Seca 254 Hamburg, Germany). Body weight was measured to the nearest $0.10 \mathrm{~kg}$, lightly dressed (and without diapers) using a portable electronic weight scale (Seca 254 Hamburg, Germany). Waist circumference will be measured with a non-elastic tape at the top of the iliac crest $[75,76]$.

Blood pressure Blood pressure will be measured with a digital vital signs monitor using an appropriate size cuff (WelchAllyn PROBP 3400 series, Skaneateles Falls, NY: USA), in a quiet room between 7 and 9 a.m. Two measurements will be taken after 5 and 10 min of rest with the participant in a sitting position, with the arm relaxed and supported so that the cubital fossa is at the level of the heart. Measurements will be taken from the right arm using an appropriate cuff size. A third measurement will be taken if the difference between the previous two measurements was more than $2 \mathrm{~mm} \mathrm{Hg}$ [77-79].

Retinal microvasculature Changes in the retinal microvessels are believed to precede chronic conditions such as heart disease and diabetes [80, 81]. Retinal microvasculature will be assessed by retinal photography, as a direct and non-invasive visualization of the body's microvasculature. The image of each eye will be recorded using a portable retinal camera (Optomed Smartscope Pro, Finland) according to the manufacturer instructions. The child will be asked to look into the camera and focus on the red dot that will be floating in their visual space. Once the eye is focused and in the right position, a photo will be taken of each eye [82]. Images will be analysed for arterial and venular diameters, arteriovenous ratio and vessel tortuosity using appropriate software.

Bone mineral density Bone mineral density will be assessed using a portable ultrasound bone sonometer (Pediatric Sunlight MiniOmni, BeamMed Ltd., Israel) which non-invasivly measures bone speed of sound (in meters per second). Results and then expressed as age- and gender-matched Z-scores and percentiles. The measurements will be performed on the left leg at the mid-tibia (point between the apex of the medial malleolus and the distal patellar apex), while the participant and the operator are comfortably seated, according to the protocols recommended by the manufacturer (www.beammed.com).

Mother's health during pregnancy The family survey will assess several variables about the mother's health during pregnancy that are known to be related with our primary outcome and/or cardiovascular health of the children. We will assess weight gain during pregnancy [83], weeks of gestation [84], type of birth delivery (vaginal delivery, instrumental vaginal delivery or caesarean) $[85,86]$, singleton and multiparous pregnancy [87], health problems during pregnancy (Hypertension or Pre-eclampsia, Gestational Diabetes, Type II Diabetes, Type I Diabetes, Vitamin D deficiency, Anaemia, Cardiovascular disease, Thyroid dysfunction) [88-92] smoking and alcohol consumption during pregnancy [93], vitamins supplementation and physical activity habits [94].

Educators' demographics and self-efficacy Educator' age, gender, level of schooling, qualification and years of experience will be self-reported. Educators will also complete a modified version of the teacher self-efficacy scale of Bandura [95]. The questionnaire will assess instructional self-efficacy; disciplinary self-efficacy and selfefficacy to create a positive childcare climate.

Childcare environmental rating We will rate ECEC centres with the Infant/Toddler Environment Rating Scale-revised edition (ITERS-R). This scale is designed to assess the structural and process quality of early childhood programs. The scale contains 39 items that comprise seven subscales: (i) space and furnishings; (ii) personal care routines; (iii) listening and talking; (iv) activities; (v) interaction; (vi) program structure; and (vii) parents and staff [96].

\section{Sample Size}

\section{Sample size and power calculations}

We anticipate an effect size of 0.5 for the between-group difference in cognitive development and an intraclass correlation (ICC) of $0.01-0.05$. The proposed design has 16 services ( 8 per group) and 16 children completing per service. Allowing for participation of 18 eligible children with two dropouts per service [10 \%] gives a total sample size of 256. This reduces to an effective sample size of 200-254 (with rounding) based on ICCs of 0.05-0.01. The power to detect an effect size of 0.5 with these sample sizes ranges from $0.87-0.96$ at an alpha level of 0.05 .

\section{Randomisation and allocation}

Research assistants will conduct baseline assessments before randomization. ECEC services will be randomly allocated to either intervention or control condition. We will create a randomization sequence using excel 2011 (Microsoft, Redmond, WA, USA) with a 1:1 allocation using random block sizes of 2, 4 and 6. An independent statistician will conduct this procedure and the data manager will perform the random allocation of services. 


\section{Blinding}

Randomization and group allocation will be blinded for the data collectors of this RCT.

\section{Implementation}

Process evaluation will include fidelity of the implementation, consistency of the implementation across ECEC services, and barriers to implementation. To assess fidelity and consistency of the intervention, educators will complete a weekly checklist documenting the activities that were undertaken in the ECEC centre. During the intervention period educators will receive monthly visits from the research team for process evaluation. During these visits we will assess objective information on the sitting time in a small random sample $(10 \%)$ of toddlers to monitor the implementation of the intervention. On these occasions we will also assess the educators' perceived barriers of the intervention implementation with semi-structured interviews. Attendance rates for each child will also be collected to account for the dose of intervention received.

\section{Data Management}

In compliance with the University's policies, all studyrelated information will be stored securely at the University, in locked filing cabinets in locked offices, and will be treated as strictly confidential.

Data will be entered directly into existing, secure online or offline databases. All databases are secured by password-protected access systems. For quality control of data entry, another member of the research team will do a random check of data entry quality in $10 \%$ of sample cases. The confidentially and anonymity of the data will be secured through a coding system of the participants. Re-use of the anonymised data will be made available for future projects by arrangement. All participants will also have access to their own results. A data monitoring committee will not be established due to the fact that the interventions poses no risk to the participants.

\section{Statistical analysis \\ Primary analysis}

Analysis of the primary outcome will be conducted using a linear or generalized mixed model in STATA 14.0 (or higher). The mixed model will contain a random effect for time and service nested within group. Degrees of freedom will be altered manually in the code to adjust for the effect of clustering. These established procedures are well documented by Murray [97] and have been used previously by our research institute to analyse a similar study in primary schools [98]. No interim analyses are planned.

\section{Secondary analyses}

Mixed models will also be used to analyse the differences between treatment and control groups for all continuous secondary outcome variables.

\section{Mediation and moderation analyses}

Two types of analyses will be conducted to explore the theoretical assumptions of the intervention. First, hypothesised mediators of change in cognitive development (e.g., educator self-efficacy) will be examined using multilevel linear analysis and a product-of-coefficients test appropriate for cluster RCTs. Potential moderators of the intervention effects (e.g., child age and gender) will also be explored using multi-level modelling.

\section{Discussion}

Evidence suggests that early childhood development is critical for the establishment of the foundations for future learning, and social and health outcomes [6, 7] and even small improvements in cognitive development and EF during early childhood "could shift the entire distribution of outcomes in a salutary direction and yield large improvements in health, wealth and crime rate for a nation" [8]. The proposed RCT represents the first study aimed to assess the effects of decreased sitting on cognitive development and EF in toddlers. The results of this study could significantly inform SB and PA guidelines for the early years, as SB experimental studies and studies with toddlers using objectively-measured SB and PA have been identified as critical to enhance the quality of the evidence base $[99,100]$. Moreover, research regarding the potential harms of excessive sitting and benefits of PA in toddlers are scarce [32, 44] and a call has been made for further research on cognitive and psychosocial development to inform SB guidelines for the early years due to the lack of evidence in this area [101]. This RCT aims to address this knowledge deficit.

This RCT will also take an innovative approach and use unique methodologies to significantly increase current understanding. In children SBs such as television viewing and overall screen time have been commonly studied and rely on parent-proxy reports; however, they do not represent the total amount of habitual sedentary time. This project will provide new insights on SB and cognitive development in toddlers by: (i) including direct comprehensive and standardized measures of cognitive development for young children; (ii) objectively assessing SB and PA with accelerometry (iii) testing independent associations of SB and cognitive development (e.g. adjusting the analysis for PA levels); (iv) testing mediators of change in cognitive development and moderators of the intervention effects and (v) using a cluster RCT design which is critical for establishing cause and effect relationships and doseresponse associations. 
Through better understanding of the effects of reducing sitting time on cognitive development and EF in disadvantaged toddlers, this RCT has the potential to inform programs and policies designed to optimize developmental and health outcomes in young children, specifically in those from a disadvantaged backgrounds.

This project has the potential to inform future government policies and programs focused on SB and PA such as updating the National Physical Activity Recommendations for Children $0-5$ years [102].

In conclusion, the knowledge generated by this project could be beneficial, nationally and internationally, for: i) parents aiming to optimize developmental outcomes for their children; ii) early childhood educators, clinicians, health care providers, and health promoters, aiming to enhance developmental outcomes in young children through intervention programs; iii) government departments seeking to develop evidence-based guidelines; and iv) researchers seeking to evaluate and translate effective programs to give young children the best start in life.

\section{Additional file}

Additional file 1: Table S1. Effects of reduced sitting time on toddlers' cognitive development: a cluster randomized controlled trial. Trial registration data. (DOCX $76 \mathrm{~kb})$

\section{Abbreviations}

ECEC: Early childhood education and care; EF(s): Executive function(s); PA: Physical activity(ies); SB: Sedentary behavior(s)

\section{Acknowledgements}

Not applicable.

\section{Funding}

This project was funded by the Australian Research Council (DE150101921). Rute Santos has a Discovery Early Career Research Award from the Australian Research Council (DE150101921). Dylan Cliff has a Discovery Early Career Research Award from the Australian Research Council (DE140101588). The funding source had no role in the design of the study, and will not have any role during its execution, analysis, interpretation of the data, or decision to submit results.

\section{Availability of data and materials}

The datasets of the current study are available from the corresponding author on reasonable request.

\section{Authors' contributions}

All authors made substantial contributions to conception and design of the study, have been involved in drafting the manuscript and revising it critically for important intellectual content. All authors read and approved the final manuscript.

\section{Authors' information}

Nothing to report.

\section{Competing interests}

The authors declare that they have no competing interests.

\section{Ethics approval and consent to participate}

The University of Wollongong's Human Research Ethics Committee approved the study (HE15/236) and this RCT was registered in the Australian and New Zealand Clinical Trials Registry (ACTRN12616000471482, 11/04/2016, retrospectively registered) (see Additional file 1: Table S1 for trial registration data details). Informed written consents will be obtained from the Educators and children's parents or guardians.

\section{Author details}

${ }^{1}$ Early Start Research Institute, School of Education, Faculty of Social Sciences, University of Wollongong, Northfields Avenue, Wollongong, NSW 2522, Australia. ${ }^{2}$ Research Centre in Physical Activity, Health and Leisure, Faculty of Sport, University of Porto, Porto, Portugal. ${ }^{3}$ Illawarra Health and Medical Research Institute, University of Wollongong, Wollongong, Australia.

Received: 27 June 2016 Accepted: 28 October 2016

Published online: 09 November 2016

\section{References}

1. CDCHU. Center on the developing child at harvard university. A sciencebased framework for early childhood policy: Using evidence to improve outcomes in learning, behavior, and health for vulnerable children. Cambridge: Center on the Developing Child at Harvard University; 2007. http://developingchild.harvard.edu/library/reports_and_working_papers/ policy_framework/.

2. Bradley RH, Corwyn RF. Socioeconomic status and child development. Annu Rev Psychol. 2002;53:371-99.

3. Noble KG, McCandliss BD, Farah MJ. Socioeconomic gradients predict individual differences in neurocognitive abilities. Dev Sci. 2007;10(4):464-80,

4. Lipina SJ, Martelli MI, Vuelta B, Colombo JA. Performance on the a-not-b task of argentinean infants from unsatisfied and satisfied basic needs homes. Rev Interam Psicol. 2005;39:49-60.

5. Hair NL, Hanson JL, Wolfe BL, Pollak SD. Association of child poverty, brain development, and academic achievement. JAMA Pediatr. 2015;169(9):822-9.

6. Shonkoff JP. Protecting brains, not simply stimulating minds. Science. 2011; 333(6045):982-3.

7. Diamond A. Executive functions. Annu Rev Psychol. 2013:64:135-68.

8. Moffitt TE, Arseneault L, Belsky D, Dickson N, Hancox RJ, Harrington H, et al. A gradient of childhood self-control predicts health, wealth, and public safety. Proc Natl Acad Sci U S A. 2011;108(7):2693-8.

9. Blair C. School readiness. Integrating cognition and emotion in a neurobiological conceptualization of children's functioning at school entry. Am Psychol. 2002;57(2):111-27.

10. Blair C, Razza RP. Relating effortful control, executive function, and false belief understanding to emerging math and literacy ability in kindergarten. Child Dev. 2007:78(2):647-63.

11. Fitzpatrick C, McKinnon RD, Blair CB, Willoughby MT. Do preschool executive function skills explain the school readiness gap between advantaged and disadvantaged children? Learn Instr. 2014;30:25-31.

12. Bull R, Espy KA, Wiebe SA. Short-term memory, working memory, and executive functioning in preschoolers: Longitudinal predictors of mathematical achievement at age 7 years. Dev Neuropsychol. 2008;33(3): 205-28

13. Fitzpatrick C, Pagani LS. Toddler working memory skills predict kindergarten school readiness. Intelligence. 2012;40:205-12.

14. Evans GW. The environment of childhood poverty. Am Psychol. 2004;59(2): 77-92.

15. Shonkoff J, Phillips D. From neurons to neighbourhoods: The science of early childhood development. Washington: National Academy Press; 2000

16. Hackman DA, Farah MJ. Socioeconomic status and the developing brain. Trends Cogn Sci. 2009:13(2):65-73.

17. Evans GW, Schamberg MA. Childhood poverty, chronic stress, and adult working memory. Proc Natl Acad Sci U S A. 2009;106(16):6545-9.

18. Diamond A, Lee K. Interventions shown to aid executive function development in children 4 to 12 years old. Science. 2011;333(6045):959-64.

19. Shonkoff JP, Fisher PA. Rethinking evidence-based practice and twogeneration programs to create the future of early childhood policy. Dev Psychopathol. 2013:25(4 Pt 2):1635-53.

20. Luby J, Belden A, Botteron K, Marrus N, Harms MP, Babb C, et al. The effects of poverty on childhood brain development: The mediating effect of caregiving and stressful life events. JAMA Pediatr. 2013;167(12):1135-42. 
21. Shonkoff JP. Changing the narrative for early childhood investment. JAMA Pediatr. 2014;168(2):105-6.

22. Sibley BA, Etnier JL. The relationship between physical activity and cognition in children: A meta-analysis. Pediatr Exerc Sci. 2003;15:243-56.

23. Hillman $\mathrm{CH}$, Erickson Kl, Kramer AF. Be smart, exercise your heart: Exercise effects on brain and cognition. Nat Rev Neurosci. 2008;9(1):58-65.

24. Porter LS. The impact of physical-physiological activity on infants' growth and development. Nurs Res. 1972:21(3):210-9.

25. Janz KF, Burns TL, Levy SM. Tracking of activity and sedentary behaviors in childhood: The iowa bone development study. Am J Prev Med. 2005;29(3): 171-8.

26. SBRN. Sedentary behaviour research network. Letter to the editor: Standardized use of the terms "sedentary" and "sedentary behaviours. Appl Physiol Nutr Metab. 2012;37:540-2.

27. Pate RR, O'Neill JR, Lobelo F. The evolving definition of "sedentary". Exerc Sport Sci Rev. 2008;36(4):173-8.

28. Tremblay MS, Colley RC, Saunders TJ, Healy GN, Owen N. Physiological and health implications of a sedentary lifestyle. Appl Physiol Nutr Metab. 2010; 35(6):725-40.

29. Chinapaw MJ, Proper Kl, Brug J, van Mechelen W, Singh AS. Relationship between young peoples' sedentary behaviour and biomedical health indicators: A systematic review of prospective studies. Obes Rev. 2011;12(7): e621-632.

30. Voss MW, Carr L, Clark R, Weng T. Revenge of the "sit" ii: Does lifestyle impact neuronal and cognitive health through distinct mechanisms associated with sedentary behavior and physical activity. Ment Health and Phys Act. 2014;7(1):9-24.

31. Cliff DP, Hesketh KD, Vella SA, Hinkley T, Tsiros MD, Ridgers ND, et al. Objectively measured sedentary behaviour and health and development in children and adolescents: Systematic review and meta-analysis. Obes Rev. 2016;17(4):330-44

32. Cardon G, Van Cauwenberghe E, De Bourdeaudhuij I. What do we know about physical activity in infants and toddlers: A review of the literature and future research directions. Sci Sports. 2011;26:127-30.

33. Certain LK, Kahn RS. Prevalence, correlates, and trajectory of television viewing among infants and toddlers. Pediatrics. 2002;109(4):634-42.

34. Zimmerman FJ, Christakis DA, Meltzoff AN. Television and dvd/video viewing in children younger than 2 years. Arch Pediatr Adolesc Med. 2007; 161(5):473-9.

35. Reilly JJ. Physical activity, sedentary behaviour and energy balance in the preschool child: Opportunities for early obesity prevention. Proc Nutr Soc. 2008;67(3):317-25.

36. Vale S, Silva P, Santos R, Soares-Miranda L, Mota J. Compliance with physical activity guidelines in preschool children. J Sports Sci. 2010;28(6):603-8.

37. Hnatiuk JA, Salmon J, Hinkley T, Okely AD, Trost S. A review of preschoo children's physical activity and sedentary time using objective measures. Am J Prev Med. 2014:47(4):487-97.

38. Bornstein DB, Beets MW, Byun W, Mclver K. Accelerometer-derived physical activity levels of preschoolers: A meta-analysis. J Sci Med Sport. 2011;14(6): 504-11.

39. Hinkley T, Salmon J, Okely AD, Crawford D, Hesketh K. Preschoolers' physical activity, screen time, and compliance with recommendations. Med Sci Sports Exerc. 2012:44(3):458-65

40. Gubbels JS, Kremers SP, van Kann DH, Stafleu A, Candel MJ, Dagnelie PC, et al. Interaction between physical environment, social environment, and child characteristics in determining physical activity at child care. Health Psychol. 2011;30(1):84-90.

41. Pate RR, Mclver K, Dowda M, Brown WH, Addy C. Directly observed physical activity levels in preschool children. J Sch Health. 2008;78(8):438-44.

42. Reilly JJ. Low levels of objectively measured physical activity in preschoolers in child care. Med Sci Sports Exerc. 2010;42(3):502-7.

43. Timmons BW, Leblanc AG, Carson V, Connor Gorber S, Dillman C, Janssen I, et al. Systematic review of physical activity and health in the early years (aged 0-4 years). Appl Physiol Nutr Metab. 2012;37(4):773-92.

44. Worobey J. Physical activity in infancy: Developmental aspects, measurement, and importance. Am J Clin Nutr. 2014;99(3):729S-33S.

45. Hawkins SS, Law C. A review of risk factors for overweight in preschool children: A policy perspective. Int J Pediatr Obes. 2006;1(4):195-209.

46. Martinez-Gomez D, Tucker J, Heelan KA, Welk GJ, Eisenmann JC. Associations between sedentary behavior and blood pressure in young children. Arch Pediatr Adolesc Med. 2009;163(8):724-30.
47. Wosje KS, Khoury PR, Claytor RP, Copeland KA, Kalkwarf HJ, Daniels SR. Adiposity and tv viewing are related to less bone accrual in young children. J Pediatr. 2009;154(1):79-85. e72.

48. Zimmerman FJ, Christakis DA. Associations between content types of early media exposure and subsequent attentional problems. Pediatrics. 2007;120(5):986-92.

49. Zimmerman FJ, Christakis DA, Meltzoff AN. Associations between media viewing and language development in children under age 2 years. Pediatr. 2007;151(4):364-8.

50. Hinkley T, Teychenne M, Downing KL, Ball K, Salmon J, Hesketh KD. Early childhood physical activity, sedentary behaviors and psychosocial wellbeing: A systematic review. Prev Med. 2014;62:182-92.

51. Carson V, Hunter S, Kuzik N, Wiebe SA, Spence JC, Friedman A, et al. Systematic review of physical activity and cognitive development in early childhood. J Sci Med Sport. 2016;19(7):573-8.

52. Zimmerman FJ, Christakis DA. Children's television viewing and cognitive outcomes: A longitudinal analysis of national data. Arch Pediatr Adolesc Med. 2005;159(7):619-25.

53. Pink B. Technical paper. Socio-economic indexes for areas (seifa). Australian bureau of statistics. Catalogue no. 2033.0.55.001. Canberra: Australian Bureau of Statistics; 2011.

54. WMA. World medical association. World medical association handbook of declarations. Farney Voltaire: World Medical Association; 1989.

55. Bandura A. Health promotion by social cognitive means. Health Educ Behav. 2004;31(2):143-64

56. Bandura A. Social foundations of thought and action: A social cognitive theory. Michigan: Prentice-Hall; 1986.

57. Owen N, Salmon J, Koohsari MJ, Turrell G, Giles-Corti B. Sedentary behaviour and health: Mapping environmental and social contexts to underpin chronic disease prevention. Br J Sports Med. 2014;48(3):174-7.

58. Cornelius M, Armel KC, Hoffman K, Allen L, Bryson SW, Desai M, et al. Increasing energy- and greenhouse gas-saving behaviors among adolescents: A school-based cluster-randomized controlled trial. Energ Effic. 2014;7:217-42.

59. Bayley N. Bayley scales of infant and toddler development-third edition. San Antonio: Harcourt Assessment; 2006.

60. Miller MR, Giesbrecht GF, Müller U, Mclnerney RJ, Kerns KA. A latent variable approach to determining the structure of executive function in preschool children. J Cog Dev. 2012;13:395-423.

61. Howard SJ, Melhuish E. An early years toolbox for assessing early executive function, language, self-regulation, and social development: Validity, reliability, and preliminary norms. J Psychoeduc Assess. 2016:1-21. http://jpa. sagepub.com/content/early/2016/02/26/0734282916633009.full.pdf+html.

62. Davies G, Reilly JJ, McGowan AJ, Dall PM, Granat MH, Paton JY. Validity, practical utility, and reliability of the activpal in preschool children. Med Sci Sports Exerc. 2012;44(4):761-8.

63. Obeid J, Nguyen T, Gabel L, Timmons BW. Physical activity in ontario preschoolers: Prevalence and measurement issues. Appl Physiol Nutr Metab. 2011;36(2):291-7.

64. Janssen X, Cliff DP, Reilly JJ, Hinkley T, Jones RA, Batterham M, et al. Validation of activpal defined sedentary time and breaks in sedentary time in 4- to 6-year-olds. Pediatr Exerc Sci. 2014;26(1):110-7.

65. Trost SG, Fees BS, Haar SJ, Murray AD, Crowe LK. Identification and validity of accelerometer cut-points for toddlers. Obesity. 2012;20(11):2317-9.

66. Van Cauwenberghe E, Gubbels J, De Bourdeaudhuij I, Cardon G. Feasibility and validity of accelerometer measurements to assess physical activity in toddlers. Int J Behav Nutr Phys Act. 2011;8:67.

67. Graffar M. Une méthode de classification sociale d'echantillons de population. Courrier. 1956;6:455-9.

68. World health organization. Guidelines for controlling and monitoring the tobacco epidemic. Geneva: WHO; 1997.

69. NIAAA. Recomended alcohol questions. National institute of alcohol abuse and alcoholism. Maryland: 2003. Available at: Http://www.Niaaa.Nih.Gov/ research/guidelines-and-resources/recommended-alcohol-questions. Accessed 20 Feb 2014

70. Spruyt K, Gozal D. Pediatric sleep questionnaires as diagnostic or epidemiological tools: A review of currently available instruments. Sleep Med Rev. 2011:15(1):19-32

71. McGreavey JA, Donnan PT, Pagliari HC, Sullivan FM. The tayside children's sleep questionnaire: A simple tool to evaluate sleep problems in young children. Child Care Health Dev. 2005;31(5):539-44.

72. Goodman R. Psychometric properties of the strengths and difficulties questionnaire. J Am Acad Child Adolesc Psychiatry. 2001;40(11):1337-45. 
73. Hawes DJ, Dadds MR. Australian data and psychometric properties of the strengths and difficulties questionnaire. Aust N Z J Psychiatry. 2004;38(8): 644-51.

74. Lohman TG, Roche AF, Martorell F. Anthropometric standardization reference manual. Champaign: Human Kinetics Books; 1988.

75. Cornier MA, Despres JP, Davis N, Grossniklaus DA, Klein S, Lamarche B, et al. Assessing adiposity: A scientific statement from the american heart association. Circulation. 2011;124(18):1996-2019.

76. NHANES. Anthropometry procedures manual. Atlanta: NHANES; 2013.

77. McCrindle BW. Assessment and management of hypertension in children and adolescents. Nat Rev Cardiol. 2010;7(3):155-63.

78. Campbell NR, McKay DW, Chockalingam A, Fodor JG. Errors in assessment of blood pressure: Sphygmomanometers and blood pressure cuffs. Can J Public Health. 1994;85 Suppl 2:S22-25.

79. Mourad A, Carney S, Gillies A, Jones B, Nanra R, Trevillian P. Arm position and blood pressure: A risk factor for hypertension? J Hum Hypertens. 2003; 17(6):389-95.

80. Gishti O, Jaddoe WW, Felix JF, Klaver CC, Hofman A, Wong TY, et al. Retinal microvasculature and cardiovascular health in childhood. Pediatrics. 2015; 135(4):678-85.

81. Wong TY, Klein R, Klein BE, Tielsch JM, Hubbard L, Nieto FJ. Retinal microvascular abnormalities and their relationship with hypertension, cardiovascular disease, and mortality. Surv Ophthalmol. 2001;46(1):59-80.

82. Optomed. User's manual optomed smartscope pro \& smartscope fa. Manual version: Rev 8.0. Oulo: Optomed Oy; 2015.

83. Oken E, Rifas-Shiman SL, Field AE, Frazier AL, Gillman MW. Maternal gestational weight gain and offspring weight in adolescence. Obstet Gynecol. 2008;112(5):999-1006

84. Rose O, Blanco E, Martinez SM, Sim EK, Castillo M, Lozoff B, et al. Developmental scores at 1 year with increasing gestational age, 37-41 weeks. Pediatrics. 2013;131(5):e1475-1481.

85. Khalaf SY, O'Neill SM, O'Keeffe LM, Henriksen TB, Kenny LC, Cryan JF, et al. The impact of obstetric mode of delivery on childhood behavior. Soc Psychiatry Psychiatr Epidemiol. 2015;50(10):1557-67.

86. Neu J, Rushing J. Cesarean versus vaginal delivery: Long-term infant outcomes and the hygiene hypothesis. Clin Perinatol. 2011;38(2):321-31.

87. Feldman R, Eidelman Al. Does a triplet birth pose a special risk for infant development? Assessing cognitive development in relation to intrauterine growth and mother-infant interaction across the first 2 years. Pediatrics. 2005:115(2):443-52.

88. Davis EF, Newton L, Lewandowski AJ, Lazdam M, Kelly BA, Kyriakou T, et al. Pre-eclampsia and offspring cardiovascular health: Mechanistic insights from experimental studies. Clin Sci (Lond). 2012;123(2):53-72.

89. Davis EF, Lazdam M, Lewandowski AJ, Worton SA, Kelly B, Kenworthy Y, et al. Cardiovascular risk factors in children and young adults born to preeclamptic pregnancies: A systematic review. Pediatrics. 2012;129(6): e1552-1561.

90. Heikura U, Hartikainen AL, Nordstrom T, Pouta A, Taanila A, Jarvelin MR. Maternal hypertensive disorders during pregnancy and mild cognitive limitations in the offspring. Paediatr Perinat Epidemiol. 2013;27(2):188-98.

91. Henrichs J, Bongers-Schokking JJ, Schenk JJ, Ghassabian A, Schmidt HG, Visser TJ, et al. Maternal thyroid function during early pregnancy and cognitive functioning in early childhood: The generation $r$ study. J Clin Endocrinol Metab. 2010;95(9):4227-34.

92. Morse NL. Benefits of docosahexaenoic acid, folic acid, vitamin d and iodine on foetal and infant brain development and function following materna supplementation during pregnancy and lactation. Nutrients. 2012;4(7):799-840

93. Polanska K, Jurewicz J, Hanke W. Smoking and alcohol drinking during pregnancy as the risk factors for poor child neurodevelopment - a review of epidemiological studies. Int J Occup Med Environ Health. 2015;28(3):419-43.

94. Barakat R, Perales M, Garatachea N, Ruiz JR, Lucia A. Exercise during pregnancy. A narrative review asking: What do we know? Br J Sports Med. 2015;49(21): 1377-81.

95. Bandura A. Guide for constructing self-efficacy scales. In: Pajares F, Urban T, editors. Self-efficacy beliefs of adolescents, vol. 5. Greenwich: Information Age Publishing; 2006. p. 307-37.

96. Harms T, Cryer D, Clifford RM. Infant/toddler environment rating scale revised edition. New York: Teachers College Press; 2003.

97. Murray DH. Design and analysis of group-randomized trials. New York: Oxford University Press; 1998.
98. Okely AD, Hardy LL, Pearson P, McKeen K, Batterham M, Puglisi L. Physical activity in linguistically diverse communities research and evaluation project. Final report for the nsw department of education and communities. 2011.

99. Okely $A D$, Jones RA. Sedentary behaviour recommendations for early childhood. In: Encyclopedia on Early Childhood Development [online] http://wwwchild-encyclopediacom/pages/PDF/physical_activitypdf Retrived Feb 1 2014. Edited by Tremblay RE, Boivin M, Peters RD. Montreal, Quebec: Centre of Excellence for Early Childhood Development and Strategic Knowledge Cluster on Early Child Development.

100. LeBlanc AG, Spence JC, Carson V, Connor Gorber S, Dillman C, Janssen I, et al. Systematic review of sedentary behaviour and health indicators in the early years (aged 0-4 years). Appl Physiol Nutr Metab. 2012;37(4):753-72.

101. Tremblay MS, Leblanc AG, Carson V, Choquette L, Connor Gorber S, Dillman C, et al. Canadian sedentary behaviour guidelines for the early years (aged 0-4 years). Appl Physiol Nutr Metab. 2012;37(2):370-91.

102. DOHA. National physical activity recommendations for children 0-5 years. Australia. http://www.health.gov.au Accessed 28 Feb 2014.

\section{Submit your next manuscript to BioMed Central and we will help you at every step:}

- We accept pre-submission inquiries

- Our selector tool helps you to find the most relevant journal

- We provide round the clock customer support

- Convenient online submission

- Thorough peer review

- Inclusion in PubMed and all major indexing services

- Maximum visibility for your research

Submit your manuscript at www.biomedcentral.com/submit
) Biomed Central 